\title{
REFLEXÕES SOBRE A POESIA MIGRANTE NA ITÁLIA
}

\author{
Vera Lúcia de OLIVEIRA (Università di Perugia, Itália)1 \\ "Amem o imigrante, porque vocês já foram imigrantes no Egito."
}

(Deuteronômio, 10,19)

"A minha pátria é a língua portuguesa", escreveu o grande poeta Fernando Pessoa; "o meu país é o meu corpo", afirmou Tahar Lamri, escritor argelino que vive há muitos anos na Itália e que escreve em italiano. Para os escritores, a pátria pode ser um país, uma língua, uma história, o próprio corpo, a memória, a remoção do passado e o vazio que deriva desse processo e que impõe a necessidade de recompor uma nova identidade em outro lugar, em outro idioma. Pode ser também uma mala, com poucos objetos salvos de uma vida anterior, que eles arrastam como as paredes da alma, como caracóis levando nas costas suas casas.

Que tipo de relação instauram os poetas e os escritores nômades, migrantes ou mesmo exilados com os lugares e com as línguas em que vivem? Tais questões, também tão ligadas ao meu percurso poético entre duas línguas, e sobre as quais me debrucei precedentemente em outros ensaios, serão aqui brevemente focalizadas na literatura produzida por autores estrangeiros que escolheram a língua italiana como língua literária, em parte de suas obras ou em toda a obra.

A Itália, país que viveu um consistente movimento migratório, com milhões de italianos que se radicaram em muitos países, inclusive no Brasil (calcula-se que há sessenta milhões de indivíduos de origem italiana fora da Itália), vive hoje um processo inverso, ou seja, o de uma nação que se tornou meta de um grande número de imigrantes, alguns dos quais adotaram a língua italiana como língua literária e poética. Tais escritores são geralmente definidos pela crítica italiana “escritores migrantes”2. 
Para a estudiosa Franca Sinopoli, o escritor migrante é "aquele que muda pátria e cultura, rejeitando os vínculos condicionantes do ambiente de origem e transformando em tema, em suas obras, a recusa da pátria sedentária, constituída por vínculos de sangue, solo, língua e cultura."3 E afirma ainda que seria necessário, para a abordagem de tal produção, não tanto uma hiper-especialização dos estudos dedicados à literatura italiana, no caso deste país, bem como de uma mudança muito mais profunda e radical, de horizontes, de perspectivas e de pressupostos críticos, que considerasse tal fenômeno dentro dos diversos cruzamentos e enfoques da literatura européia da diáspora, ou seja, como um patrimônio transnacional característico dos diversos países europeus.4 Os próprios estudos comparatísticos interculturais se rearticulariam assim de forma a levar em conta textos literários provenientes de zonas e de cânones literários muito distintos e diversificados.

$\mathrm{Na}$ Itália, no entanto, muitos dos próprios autores englobados pela crítica em tal categoria, "literatura da migração", que atesta a existência de um movimento literário rico e articulado, rejeitam-na, denunciando uma marginalização implícita no termo, já que separa essa produção daquela considerada ortodoxamente italiana. Com efeito, o termo não pode e não deve indicar uma diminuzio em relação à literatura italiana em geral, como se tais autores devessem a todo momento confirmar a própria maestria no uso do novo idioma, além do fato de que qualquer inovação formal ou violação do código efetuada por eles é vista, muitas vezes, não como uma luta corpo a corpo com a palavra, no esforço de afinamento da forma, mas como imperícia no manejo do idioma de Dante.

Uma outra objeção que poderíamos fazer a tal denominação está no fato de que generaliza experiências e obras de uma diversidade intrínseca. De fato, o termo "migrante" não distingue experiências tão diferentes, como a do exilado, a do refugiado, a do expatriado ou a do emigrado. Essa distinção é importante, pois dela depende a configuração que certos temas vão assumir na obra de determinados autores. É evidente que o exilado vai incorporar em sua produção o estigma, como afirma Edward W. Said, de ser um outsider. Por outro lado, os expatriados vivem voluntariamente em um país estrangeiro, por breves ou longos períodos, e os motivos podem ser os mais diversos, como o do estudo, que é em geral uma experiência positiva. Quanto ao emigrado, ele 
tem status ambíguo, deixa o país por uma sua escolha, mas vive frequentemente o mesmo penoso desarraigamento do exilado.

Segundo Said, o exilado tem obsessão pela sua condição e tal sentimento determina a sua vida e obra. Exemplos de grandes escritores exilados, marcados pelo sentimento de orfandade e solidão, são Dante, Joyce, Conrad, Adorno. 5 A estes, poderemos acrescentar muitos outros, como Iosif Brodskij, Günter Grass, Samuel Beckett, Eugene Ionesco, Ezra Pound, Paul Celan, Filippo Marinetti e Giuseppe Ungaretti e, no âmbito da língua portuguesa, podemos de alguma forma englobar autores como Camilo Pessanha, Fernando Pessoa, Jorge de Sena, Murilo Mendes, Clarice Lispector e até Guimarães Rosa. O que une tais escritores é o fato de serem transnacionais, plurilíngues, nômades, e também o fato de que cruzaram diversas tradições literárias e culturais, inovando talvez mesmo por este motivo, pois a pluralidade cultural proporciona a experiência da alteridade, que marca e transforma qualquer indivíduo.

A Itália não tem um passado colonial significativo, embora tenha feito muito esforço para obter colônias. Teve, por um breve período, três na África, a Eritréia, a Somália e a Líbia, e, na Europa, a Albânia. Tal tentativa de expansão colonial, porém, fracassou com a derrocada do regime fascista, depois da Segunda Guerra Mundial. Ao contrário de outros países europeus, ela conviveu relativamente pouco com culturas diferentes e até opostas à sua, em que outras nações adotassem a sua língua, utilizando-a inclusive para a construção de identidades híbridas e independentes, ou com literaturas geradas a partir do mesmo código linguístico, como ocorreu com outros países, como Portugal, a Espanha, a Inglaterra, a França.

O caso italiano é interessante justamente porque os indivíduos de origem estrangeira que produzem e publicam obras em italiano não têm, na maior parte dos casos, ligação com este país em função de um passado colonial. Assim, afirma justamente Franca Sinopoli, não podemos falar propriamente de literatura pós-colonial em língua italiana, como no caso das demais línguas e literaturas citadas acima6. O próprio fenômeno das culturas e identidades múltiplas, que coexistem e interagem entre si, às vezes provocando atritos ou mesmo fundindo-se de forma original, é algo de 
relativamente novo na Itália, ligado aos fluxos migratórios que viu este país, sobretudo nas últimas décadas, ao centro de um doloroso tráfico de seres humanos, capturados pela rede da criminalidade organizada, que explora multidões de pessoas em busca de uma vida melhor ou em fuga de guerras, carestias, discriminações, perseguições étnicas e políticas.

É claro que há, na Itália, a questão das identidades regionais distintas, dentro do panorama nacional, onde muitas vezes cidades próximas possuem costumes e mesmo dialetos diferentes, mas tais variedades fazem parte da realidade de tantos países, como, por exemplo, a Bélgica, a Espanha e mesmo o Brasil. Não é destas diferenças que falo aqui.

O século XX será talvez conhecido como o das migrações contínuas, nunca se assistiu antes a um tal movimento de massas de populações em fuga de todos os guetos do mundo, da miséria das periferias, do isolamento dos muros, das fronteiras que dividem os que têm o necessário e o supérfluo dos que foram despojados de tudo, até da própria dignidade. Como outros países europeus, a Itália foi atingida por esta rede e por este fluxo humano em movimento e o Mar Mediterrâneo é um grande cemitério de milhares de clandestinos que ali acharam sua sepultura, sem um nome, uma foto, uma história, uma tumba para que os parentes possam pranteá-los.

Erri de Lucca, escritor entre os maiores e mais intensos da literatura italiana contemporânea, traça, no livro Solo andata, os contornos desse drama, pondo-se na pele de tantos excluídos, seres despojados de um presente e de um futuro:

Scacciati dalla terra, siamo il seme sputato il più lontano dall'albero tagliato, fino ai campi del mare.

Servitevi di noi, giacimento di vita da sfruttare,

pianta, metallo, mani, molto più di una forza da lavoro.

Nostra patria è la cenere fresca di vecchi e di animali, è partita nel vento prima di noi, sarà arrivata già. 
Non avete mai visto migrar patrie? Noi dell'Africa sì,

s'alzano con il fumo degli incendi, si spargono a concime.7

[Expulsos da terra, somos a semente cuspida distante da árvore abatida, até aos campos do mar.

Sirvam-se de nós, jazidas de vida para explorar,

planta, metal, mãos, muito mais que simples força de trabalho.

Nossa pátria é a cinza fresca de velhos e animais, partiu com o vento antes de nós, já terá chegado.

Nunca viram pátrias migrar? Nós, os da África, vimos, se levantam com a fumaça dos incêndios, se espalham como adubo.]

Além da viagem em si de tantos desesperados, muito há que se dizer também sobre o difícil processo de aclimatação e adaptação à nova terra dos que conseguem chegar e que, nesse belo país (Italia è uma parola aperta, piena d'aria [Itália é uma palavra aberta, cheia de ar], afirma De Luca8) tentam criar novas raízes. Focalizar a literatura que nasce da migração é tocar alguns dos pontos nevrálgicos dessa problemática, pois, como afirma o estudioso Armando Gnisci, um dos pioneiros em tais estudos:

Il narratore e il poeta diventano la barca che segnala il senso sull'orlo dell'abisso, la striscia disegnata intorno alla tempesta del trasloco, la canzone che risuona nel buco opaco della disperazione. Il poeta-narratore trova le parole ed 'esprime' durante il transito pericoloso. [...] Il poeta porta e significa la presenza e la forza della parola, e il suo fardello, che compone luce e opaco, voce e scrittura. 9

[O narrador e o poeta tornam-se o barco que indica significados que há até nas bordas do abismo, as ondas delineadas ao redor da tempestade da viagem, a canção que ressoa na fenda opaca do desespero. O poeta-narrador encontra as palavras certas e as exprime durante a passagem perigosa. [...] $\mathrm{O}$ poeta traz consigo e significa, ele mesmo, a presença e a força da palavra, o seu peso, que compõe luz e opacidade, voz e escrita.]

Se os políticos italianos, que aprovaram e votaram a recente lei que regulamenta a entrada e a permanência de estrangeiros na Itália, à qual denominaram, com um certo cinismo e crueldade, "Pachetto sicurezza", se lembrassem do próprio passado de imigrantes ou lessem algumas páginas dessa literatura, tomariam consciência do fato de 
que ninguém deixa a própria terra sem um motivo forte e que o sentimento de enraizamento é um dos mais intensos e intrínsecos da alma humana. Definir qualquer imigrante como um clandestino e criminá-lo pelo simples fato de que precisou deixar a sua terra é renegar a história desse país e renegar também as bases de convivência da sociedade italiana, de matriz hebraico-cristã, afeita, pois, à importância ética, religiosa e até mesmo simbólica de termos e conceitos, como migração, peregrinação, deportação e exílio.

Retomando o tema inicial, vemos que, com o passar do tempo e o assomar ao mundo das letras de um número cada vez mais consistente de escritores nômades, bem como o interesse que tal literatura híbrida despertava a nível mundial, também na Itália alguns estudiosos passaram a se interessar pela questão, descobrindo em casa própria que escritores provenientes de vários países e, às vezes, com línguas de maior difusão do que o italiano, utilizavam esse idioma em suas obras.

O início de uma literatura produzida por autores migrantes na Itália é apontado no começo da década de noventa, embora já antes escritores de várias nacionalidades tenham publicado seus livros nesse país, sem, no entanto, despertarem maior curiosidade por parte dos críticos; ao contrário, havia uma certa desconfiança e, às vezes, até prevenção em relação a essa produção, sobretudo em relação aos autores que se auto-traduziam.

A crítica indica algumas fases na produção literária da migração: uma primeira de testemunho, realizada com a ajuda de um intermediário, conhecedor tanto da língua de origem quanto da língua italiana; uma segunda fase em que se verifica uma maturação nesse processo de aquisição linguística profunda, com autores que se exprimem em italiano como em suas próprias línguas maternas; uma terceira fase em que, do memorialismo autobiográfico, se passa aos contos e romances. Alguns dentre os últimos, publicados por editores importantes, revelaram-se um fenômeno editorial que surpreendeu todos, como por exemplo os livros Lasciami andare, madre(Adelphi, 2001), de Helga Schneider, ou Sognando Palestina (Fabri Editori, 2002), de Randa Ghazy, ou ainda Scontro di civiltà per um ascensore a piazza Vittorio (Edizioni e/o, 
Roma, 2006), de Amara Lakhous, que ficaram várias semanas na lista dos mais vendidos e que foram traduzidos para várias línguas.

Muitas das grandes editoras italianas, como Feltrinelli, Baldini \& Castoldi, Bompiani, Laterza, Einaudi, já publicaram autores migrantes, mas esporadicamente, sem uma verdadeira política intercultural ou mesmo coleções específicas dedicadas a tal tema. São as editoras menores que reservam maior espaço para os novos autores, como Luppeti, Besa, Edizioni Lavoro, Fara, Ediarco, Edizioni e/o, e outras10. Destas, um número ainda menor aceita textos poéticos, como Fara, que é uma das pioneiras neste campo e que tem feito um bom trabalho de divulgação poética, também de jovens autores italianos.

Mia Leconte, uma das estudiosas da literatura da migração, afirma que a produção poética se processou de forma mais lenta e que só agora começam a se delinear algumas figuras marcantes, com vozes definidas e de incontestável qualidade11. Discordo em parte com tal afirmação, pois o fato de que só agora público e crítica comecem a notar alguns poetas de valor decorre da pouca importância que se dá, em geral na Itália, a esse gênero literário, relegado quase sempre para segundo plano, tanto pelas editoras quanto pelos estudiosos de literatura, o que não quer dizer que não encontremos bons poetas que já publicassem antes de tal data. Um elemento interessante, que caracteriza quase todos esses autores, e que os leva a uma aquisição rápida e exímia da língua italiana, é a alta escolarização que têm: a maior parte deles, apesar de exercerem, às vezes, atividades humildes, tem diploma universitário e muitos falam diversas línguas.

Talvez devamos nos questionar sobre o motivo que leva os escritores migrantes a adotarem o italiano em suas obras. Para muitos deles, esse idioma parece representar um espaço de liberdade, no qual é possível renascer com uma nova identidade, sem anular a precedente, mas, a esta, acrescentando elementos que a transformam e enriquecem. A escolha do italiano é feita em absoluta liberdade, e não se trata de uma escolha estratégica, feita em função de uma maior possibilidade de penetração no mercado internacional, pois vários deles tem línguas maternas de maior difusão no mundo. 
Em entrevistas, ensaios, artigos e textos literários, muitos desses autores, refletindo sobre o próprio percurso, demonstram uma excepcional consciência dos processos psicológicos que determinam, em indivíduos multilingues, o uso de uma ou de outra língua na criação de uma obra de arte.

António Osório, poeta português bilíngue, cuja mãe é italiana, fato que o levou a passar longos períodos da infância na Itália, afirma, a propósito da sua relação com o italiano:

Aliás eu tinha sempre comigo duas palavras, a portuguesa e a italiana, vizinhas mas ciosas de si, exigentes e qualquer delas inconciliável: esse era o meu segredo e, às vezes, infortúnio. [...] Basta-me o italiano para evocar silenciosamente os meus parentes da mão esquerda, e não ter remorsos de ser diferente deles, e ainda de não dispensar a outra terra, Florença. As línguas são depois da vida o milagre maior; a continuação das estações na nossa boca e na nossa alma: o segredo fecundo dos humanos. 12

No caso de António Osório, sua língua materna e mesmo literária é o português, pois ele afirma nunca ter conseguido, em italiano, a mesma fluência que em português, razão pela qual, segundo ele, "não é dado ter duas línguas maternas. A da pátria conta mais que a da mãe.”13

Outros autores, entre os quais podemos citar Helga Schneider e Julio Monteiro Martins14, escritores de sucesso na Itália, instauram com o novo idioma uma relação tão forte que começam, conscientemente ou não, a "esquecer" a língua materna. Essa remoção é por vezes percebida e até descrita por muitos deles:

Se tu mi domandi se oggi l'Italiano è la mia seconda lingua, io ti risponderò quello che per me è l'ovvio: che l'Italiano è invece la mia prima lingua. Perché prima lingua è quella in cui lo scrittore scrive, ma non solo, in cui l'uomo che fa il mestiere di scrittore sogna, si arrabbia, dice una parolaccia quando inceppa in un sasso, balbetta per se stesso parole "innamorate" che avrebbe detto a certe donne amate proprio in quella lingua. È la lingua dei loro figli, che diventano i loro maestri. Così, a mio parere, la prima lingua non è la lingua della nascita, ma la lingua della vita, la lingua dell'unico tempo visibile e palpabile: il tempo presente, l'unico punto accessibile del flusso della vita. La lingua dei ricordi non può essere più la prima lingua, così come non lo sarà la lingua dei progetti, dei piani del futuro, progetti di spostamenti. Dunque, niente è più naturale per me che scrivere in Italiano. Scrivo nella mia lingua. Punto e basta. 15 
[Se você me pergunta se hoje o italiano é minha segunda língua, responderei dizendo o que para mim é óbvio: que o italiano é minha primeira língua. Porque a primeira língua é aquela em que o escritor escreve, mas é também aquela em que o homem que exerce a profissão de escritor sonha, tem raiva, diz um palavrão quando tropeça em uma pedra, balbucia para si mesmo palavras "apaixonadas" que poderia ter dito a certas mulheres amadas nessa mesma língua. É a língua dos seus filhos, que se tornam os seus mestres. Assim, na minha opinião, a primeira língua não é a do nascimento, mas a língua da vida, a língua do único tempo visível e palpável: o tempo presente, o único ponto acessível do fluxo da vida. A língua das recordações não pode ser mais a primeira língua, assim como não será mais a língua dos projetos, das metas do futuro, dos planos de viagens. Portanto, nada para mim é mais natural do que escrever em italiano. Escrevo na minha língua. Ponto final.]

Tais autores parecem considerar como fundamental a dimensão do presente, em que o italiano é o código fundamental, embora, como para Helga Schneider, que tem uma experiência de relação trágica com o passado e com a figura materna, a qual abandonou a família para seguir as idéias de Hitler durante a Segunda Guerra Mundial, o passado retorne com frequência na nova língua. Nesse caso, o italiano é também o código em que ela re-elabora o abandono e a inexistência de uma relação com a figura da mãe, que passa pela negação da língua materna, base de tal relação. O italiano para ela substituiu a língua nativa e se tornou a primeira língua da interioridade, em que foi possível reconstruir uma nova relação dialógica com o mundo.

Outro poeta, o holandês Arnald de Vos, afirma que descobriu na língua italiana um concentrado de energias e forças que o levam à palavra e à escrita porque esta língua o ajudou a desenvolver a capacidade de ouvir e de se relacionar com o outro, capacidade fundamental não só na vida quotidiana, mas também na literatura. Se tantas são as respostas dadas pelos autores migrantes 16, já que diversa é percepção de como se verifica o processo de assimilação e, às vezes, de substituição de um código pelo outro, muitas outras questões relevantes solicitam o interesse do estudioso desta literatura híbrida, como, por exemplo, a dos temas recorrentes e a das características estilísticas dessa produção.

Um elemento importante da poesia migrante, bem evidenciado por Mia Leconte no ensaio que prefacia o livro Ai confini del verso, publicado em 2006, antologia que, diga-se de passagem, deixou de fora muitas vozes, é, como afirma a estudiosa, "l'alto grado di eticità, ancorato alla storia, di cui, si fa portatrice"17 [o alto grau de ética, 
ancorada à história, de que se faz porta-voz]. Tal poesia caracteriza-se, pois, pela ligação, consciente e responsável, que tem com a realidade e com a história, tanto pessoal quanto coletiva de um tempo em que comunidades e povos inteiros se deslocam de um lugar para outro em busca de melhores condições de vida:

Quello che subito balza agli occhi, al di là delle differenti identità geografiche dei poeti, è la sua "necessità": un vincolo carnale coi significati che arrivano di conseguenza con la violenza delle esperienze reali. La sua forza deriva dalla doppia componente della migrazione - il dolore e la speranza, viva, di rinascita - che conferiscono appunto fisicità e potenza al verso". 18

[O que salta logo aos olhos, para além das diferentes identidades geográficas dos poetas, é a pregnância [dessa literatura]: um vínculo carnal com os significados que chegam, assim, com a violência das experiências reais. A força deles deriva da dupla componente da migração - o sofrimento e a esperança, viva, de renascer - que conferem, justamente, concretude e potência ao verso.]

Seria, portanto, tal componente e mesmo substância incandescente e dolorosa das experiências concretas a determinar o elevado grau ético desse lirismo, e uma urgência, uma energia e uma consciência do papel lenitivo e salvífico da poesia, além da exigência de dar sentido a cada momento, de encarnar sentimentos, acontecimentos, encontros e desencontros, gestos que se perderiam para sempre, tanto do passado quanto do presente, em um novo código linguístico, que se impregna de uma força e de uma densidade que falta, por vezes, à própria poesia italiana contemporânea, como sublinham muitos estudiosos. A componente dolorosa de tal produção está ligada à experiência da migração, que muitos destes autores vivem por imposição econômica, política ou por outros motivos. Afirma, de fato, Edward W. Said que, apesar da aura às vezes romântica e quase heróica com que se considera, nas artes e na literatura, o exílio e a figura do exilado, o exílio é uma experiência permanente e insanável de fratura, de perda e de abandono, uma espécie de morte em vida: "I sucessi dell'esilio sono permanentemente inficiati dalla perdita di qualcosa che ci si è lasciati per sempre alle spale."19[Os sucessos do exílio são permanentemente invalidados pela perda de algo que se deixou para sempre para trás]. 
$\mathrm{O}$ fato de que se consiga ver algo de positivo em tal experiência humana traumática se deve ao papel e ao trabalho de poetas e escritores:

Questi e molti altri poeti e scrittori in esilio restituirono dignità a una condizione giuridicamente creata per negare dignità - negare un'identità alle persone. Dal loro esempio appare evidente che per concentrarsi sull'esilio come pena politica contemporanea, si debbano mappare territori di esperienza che vanno al di là di quelli tracciati dalla letteratura dell'esilio in sé. 20

[Estes e muitos outros poetas e escritores em exílio restituíram dignidade a uma condição juridicamente criada para negar dignidade - negar uma identidade às pessoas. Pelo exemplo deles, é evidente que, para concentrarse sobre o exílio como pena política contemporânea, se deve mapear territórios de experiências que vão muito além dos traçados pela literatura do exílio em si.]

Ora, dissemos no início que os escritores migrantes, com a necessidade de redefinir uma identidade, que é complexa e híbrida, constroem um novo tempo e espaço, uma nova casa, inventam uma pátria em que seja possível de novo viver. Às vezes, essa pátria é a língua da infância, que lutam para não perder, às vezes é a língua que a custo interiorizam, como se fosse possível nascer de novo e dar forma à realidade com um outro verbo. O senso de estranhamento ser-lhes-á para sempre inerente e intrínseco, embora, não nos esqueçamos, o sentimento de estranhamento é congênito a todo artista e escritor. Tomando emprestado à escritora brasileira, Marina Colasanti, o belo título do seu último livro, Passageira em trânsito21, podemos afirmar que todo escritor, todo poeta é um "passageiro em trânsito", pois a literatura é uma viagem, um caminho vertical ao coração das coisas e da vida. A condição do migrante é propícia, entre outras coisas, ao nascimento da poesia, mas não garante que todo migrante possa ser um escritor ou um poeta e, sobretudo, que o possa ser de forma original. Tantas são as coordenadas que se devem cruzar para que se verifique o milagre da poesia, como nos recordou emocionado Alberto Moravia, a propósito da morte trágica de Pasolini, afirmando que, de grandes poetas como Pasolini, nasciam não mais do que um ou dois em cada século.

Uma outra característica da poesia migrante, ligada ao que foi dito acima, é o fato de cada escritor inventar o seu percurso em solidão. Não há parâmetros, poéticas e 
cânones, com os quais se confrontar. Cada um tem sua história, sua bagagem de rupturas e perdas, suas línguas e identidades superpostas, suas viagens, novos amores e novos destinos, tudo combinado de forma completamente diferente de autor para autor. Não há padrões ou critérios seguros, não há um gênero predominante que defina tal literatura, e isso produz insegurança e incerteza nos autores e desinteresse por parte da crítica, que não sabe onde enquadrá-los. A tal propósito, Theodor W. Adorno, outro intelectual que assumiu a perene condição do migrante, afirma que todo intelectual, na migração, deveria reconhecer e assumir a condição de nômade solitário e buscar em si mesmo a consciência do seu percurso e do seu valor, sem esperar que esta lhe venha de fora e sem buscar, espasmodicamente, aprovação ou consenso externos. A consciência de tal condição, afirma, requer dolorosa e extrema lucidez, uma força interior muito grande e a aceitação da solidão como destino. 22

Do ponto de vista dos resultados e da qualidade estética, é essa solidão, ou seja, esses caminhos que se constroem cruzando tantos elementos díspares, a produzir a originalidade de muitos destes autores, o que leva editores e críticos a afirmar que a verdadeira novidade hoje na Itália, em campo literário, é garantida pela literatura da migração. Isso ocorre porque uma língua é um organismo vivo, em constante evolução, dá e recebe, modula a voz dos novos italianos, mas é também modulada por eles, plasmada de outra forma, o que muitas vezes gera surpresa e estranhamento, raiz de toda boa literatura. Num artigo publicado na revista de grande difusão, $L a$ Repubblica delle Donne, Alberto Rollo, editor da Feltrinelli, afirma que os autores migrantes

Stanno contribuendo a modificare la nostra narrativa. Faccio un esempio, quella della lingua: per un autore straniero c'è la ricerca della lingua perfetta o del neologismo sfrenato. Tutte e due creano uno straniamento, una sorta di sospensione, che rende la loro lettura davvero interessante”. 23

[Estão contribuindo para modificar a nossa narrativa. Faço em exemplo, o da língua: no autor estrangeiro há a busca da língua perfeita ou do neologismo desenfreado. Ambas criam um estranhamento, uma espécie de suspensão, que torna essa literatura realmente interessante.]

Um dos elementos de novidade na poesia migrante é, como dissemos, a sua concretude, a coincidência entre vida e palavra; é poesia que atravessa o corpo, sumo 
das experiências vividas, direta ou indiretamente, com toda a intensidade. O migrante tem muito a dizer, quer e precisa fazê-lo da melhor forma possível, com economia de meios e concentração semântica, e não pode se dar ao luxo de que o significado forte e vital de sua viagem se perca em malabarismos e jogos formais estéreis.

Gëzim Hajdari, extraordinário poeta ítalo-albanês, afirma que a literatura ajuda a sobreviver. Ela nos “insegna cos'è il bello e il brutto, l'amore e l'odio, la pace e la guerra, scuote le coscienze, crea mondi alternativi. [...] La poesia è anche impegno, ma non solo sul verso, sul linguaggio [...] ma nella vita.”24 [ensina o que é o belo e o feio, o amor e o ódio, a paz e a guerra, sacode as consciências, cria mundos alternativos. [...] A poesia é também empenho, não só com o verso, com a linguagem [...] mas com a vida].

Isso não quer dizer que não haja novidade formal nessa produção, ao contrário, tais autores forjam frequentemente novos termos e novas combinações entre eles, quando é necessário, quando as palavras de uso comum não são suficientes ou propícias para expressar vivências de fronteiras, borderline, que inauguram com a própria existência e as sensações e emoções de embate com o mundo. São as novas experiências que ditam uma nova gramática e formas que torcem e, às vezes, violam ou mesmo rompem com os cânones, tanto do país de origem quanto do país em que vivem.

Em relação à obra de tais autores, a poesia italiana - como a sociedade italiana em geral - parece mais estática, fechada em si mesma, refratária aos novos estímulos de um mundo em rápida transformação; sente-se que os impulsos propulsores das vanguardas se esgotaram, mas que os escritores italianos ainda estão buscando novas motivações, outros caminhos para trilhar. De fato, a sensação que se tem é de que muitos poetas falem entre si, escrevam para eles mesmos, comunidade de pares, de eleitos, sem uma verdadeira articulação com a sociedade, que - em contrapartida - os ignora.

Talvez uma possível solução para esta fase de aparente estagnação, ou pelo menos de desinteresse por parte do público, seja a de abater as fronteiras que há entre os escritores italianos e os chamados escritores migrantes, para que se fomente uma troca fértil de vivências e experiências, de perspectivas e poéticas, mesmo porque, ao 
contrário do que pensam muitos políticos, o pluralismo e mesmo o sincretismo e a mestiçagem são um valor. De fato, em um livro sobre a literatura italiana da migração, o crítico Raffaele Tadeo afirma que também a literatura italiana nasceu como literatura de viagem, de exílio e de migração e que Dante, um dos seus fundadores, é um migrante por excelência e a sua é uma língua espúria, “contaminada” 25.

Pensar em uma identidade como algo de monolítico, rígido e inalterável é negar a própria história italiana, feita de amálgamas e simbioses culturais, de empréstimos e apropriações enriquecedoras, e de uma espécie de impulso "antropofágico" (para usarmos um conceito tão característico da cultura brasileira), que a levou a assimilar e a re-elaborar de forma original o que de melhor havia em termos filosóficos, artísticos e culturais dos outros povos com os quais entrou em contato, legando à humanidade momentos únicos da nossa história, como o Humanismo e o Renascimento.

Aliás, a literatura italiana deveria se relacionar melhor não só com a literatura migrante interna, mas também com a chamada "letteratura italofona", produzida por escritores italianos de primeira e segunda gerações que vivem fora das fronteiras italianas, os quais também cruzam várias tradições em suas obras e sofrem do mesmo tipo de marginalização que vivem os autores migrantes.

Termino essas rápidas considerações sobre um tema tão complexo e fascinante augurando que se verifique, o quanto antes, uma interseção e uma confluência de intentos entre todos os escritores de língua italiana, sem distinção de origem e, sobretudo, sem hierarquias nacionalistas, já que todos buscam respostas para questões atuais, importantes sobretudo para que a sociedade perceba suas contradições e tome consciência das manipulações ideológicas, formuladas em função das idéias de exclusão e marginalização do "outro", quer este "outro" seja o estrangeiro, o pobre, o idoso, o doente. Concluo com as palavras de Mia Leconte, que compartilho inteiramente:

Ed è diventato a questo punto necessario un confronto fattivo fra scrittori migranti e autoctoni - $i$ viaggiatori immobili -, una collaborazione artistica trasversale all'insegna della contaminazione e dell'eterogeneità. Indispensabile agli uni, da un lato, per liberare la lingua della poesia italiana sfinita, autoreferenziale, da barocchismi, ermetismi $e$ sperimentazioni di una certa avanguardia ormai in retroguardia, e riascoltarla davvero attraverso la voce altrui fatta propria; e agli altri per 
essere accompagnati nella messa a punto dello strumento sonoro senza rischiare un appiattimento e un impoverimento dei risultati poetici, perché questo possa risuonare e fare eco in tutta la sua potenza, e acclimatarsi musicalmente all'interno dell'universo comune di una parola sempre più bastarda e condivisa. 26

[Tornou-se necessário, a esse ponto, um ativo debate entre escritores autóctones - os viajantes imóveis - e escritores migrantes, uma colaboração artística transversal sob o signo da contaminação e da heterogeneidade. Indispensável para os primeiros, por um lado, para liberar a língua da poesia italiana, esgotada e auto-referencial, de barroquismos, hermetismos e experimentalismos de uma certa vanguarda já em retaguarda, e re-ouvi-la pela voz do outro que a fez própria; e aos escritores migrantes, para acompanhá-los nesse processo de afinação de um instrumento sonoro sem arriscar um empobrecimento dos resultados poéticos, para que este possa ressoar e ecoar em toda a sua potência, e aclimatar-se musicalmente dentro do universo comum de uma palavra que será cada vez mais mestiça e compartilhada por todos.]

\section{REFERÊNCIAS}

AA. VV. "Atti del Secondo Seminario degli Scrittori Migranti", in Sagarana - Rivista on-line, http://sagarana.net/scuola/seminario2mercoledi_mattina.htm.

ADORNO, T. W. Mínima moralia - Meditazioni della vita offesa, trad. di R. Solmi, Torino, Einaudi, 1994.

ANOLLI, Luigi. La mente multiculturale, Bari, Edizioni Laterza, edizione speciale per Il Sole 24 Ore, Bari, 2009.

BASAGOITIA DAZZA, G. Curve, angolazioni, triangoli: l'infinito amore, Città di Castello, s.ed., 1986.

Il fiume senza fosse. Santarcangelo di Romagna, Fara Editore, 2008.

BREGOLA, D. (a cura di). Da qui verso casa, Roma, Kúmá Lettere Migranti, 2002.

- Il catalogo delle voci-Colloqui con poeti migranti, Isernia, Cosmo Ianone Editore, 2005.

BRODSKIJ, I. Dall'esilio, trad. di G. Forti e G. Buttafava, Milano, Adelphi, 2007, $5^{\text {a }}$ ed.

CAMILOTTI, S. "L'editoria italiana della letteratura della migrazione", in GNISCI, A. (a cura di),Nuovo Planetario Italiano - Geografia e antologia della letteratura della migrazione in Italia e in Europa, Troina, Città Aperta Edizioni, 2006, pp. 383-391. - Lingue e letterature in movimento (a cura di). Bologna, Bonomia University Press, 2008.

DE LUCA, E. Solo andata - righe che vanno troppo spesso a capo, Milano, Feltrinelli, 2005.

GNISCI, A. (a cura di). Nuovo Planetario Italiano - Geografia e antologia della letteratura della migrazione in Italia e in Europa, Troina, Città Aperta Edizioni, 2006. LANDI, S. (a cura di). Leggere e scrivere in tutti i sensi, Firenze, Morgana Edizioni, 2003. 
LECONTE, M. (a cura di). Ai confini del verso - Poesia della migrazione in italiano. Firenze, Le Lettere. 2006.

MEHLER, J. A., ARGENTIERI, S., CANESTRI, J. La babele dell'inconscio, Milano, Raffaello Cortina Editore, 1990.

MONTEIRO MARTINS, J. "Il brusio del mondo", in BREGOLA, D. (a cura di), Da qui verso casa, Kúmá Lettere Migranti, 2002, pp. 104-127 (116).

MUMIN AHAD, A. "Corno d'Africa. L'ex-impero italiano", in GNISCI, A. (a cura di), Nuovo Planetario Italiano - Geografia e antologia della letteratura della migrazione in Italia e in Europa. Troina, Città Aperta Edizioni, 2006, pp. 241-293.

OLIVEIRA, V. L. de. "O lugar e a língua", in Revista de Italianística, Departamento de Letras Modernas, Faculdade de Filosofia, Letras e Ciências Humanas, Universidade de São Paulo, nº. XIV, 2006, pp. 97-114.

OSÓRIO, A. Torno con te a Ulisse, a cura di G. Boni, Roma, Edizioni Empiria, 2009.

PALLOTTI, G. La seconda lingua, Milano Bompiani, 2003, $3^{\mathrm{a}}$ ed.

SAID, E. W. Dire la verità: Gli intellettuali e il potere, trad. di M. Gregorio, Milano, Feltrinelli, 1995.

- "Riflessioni sull'esilio", trad. di S. De Petris, in Scritture Migranti - Rivista di scambi interculturali, Bologna, Dipartimento di Italianistica, Università di Bologna,

Cooperativa Libraria Universitaria Editrice Bologna, 2008, pp. 127-141

SCHNEIDER, H. "Il coraggio di tagliare le lungaggini", in BREGOLA, D. (a cura di), Da qui verso casa, Roma, Kúmá Lettere Migranti, 2002, pp. 46-57.

- Lasciami andare, madre, Adelphi, 2001.

SINOPOLI, F. "Postfazione - scrivere nella lingua dell'altro", in LECONTE, M. (a cura di). Ai confini del verso - Poesia della migrazione in italiano, Firenze, Le Lettere, 2006, pp. 219-220.

TADDEO, R. Letteratura nascente. letteratura italiana della migrazione. Autori e poetiche, Raccolto Edizioni, Milano, 2006.

TITONE, R. Bilinguismo precoce e educazione bilingue, Rosa, Armando Editore, 1973.

1 Poeta. Professora de Literatura Brasileira e Portuguesa na Università di Perugia (Itália).

2 Para se ter uma idéia de quanto é amplo e articulado o fenômeno na Itália, ver a Banca de dados on-line BASILI, organizada pelo Departamento de Italianística da Universidade de Roma "La Sapienza": www.disp.let.uniroma1.it/basili2001.

3 SINOPOLI, F., "Postfazione - scrivere nella lingua dell'altro", in LECONTE, Mia (a cura di). Ai confini del verso - Poesia della migrazione in italiano, Firenze: Casa Editrice Le Lettere. 2006, pp. 219-220.

\section{Ibidem.}

5 Cf. SAID, E. W., "Riflessioni sull'esilio", trad. di Stefania De Petris, in Scritture Migranti - Rivista di scambi interculturali, Bologna, Dipartimento di Italianistica 
dell’Università di Bologna, Cooperativa Libraria Universitaria Editrice Bologna, 2008, pp. 127-141 (135).

6 SINOPOLI, F., "Postfazione - scrivere nella lingua dell'altro", op. cit., p. 216. De produção literária pós-colonial em italiano, se pode falar no caso de alguns autores originários do ex-império colonial da Itália, intelectuais que receberam instrução escolar em italiano nos respectivos países de origem, como é o caso de Garane Garane, que nasceu na Somália, Habte Weldemariam, nascido na Eritréia, Gabriella Ghermandi, originária de Addis Abeba, ou mesmo Cristina Ali Farah, nascida na Itália, mas de pai somaliano e mãe italiana. Cf. MUMIN AHAD, A, "Corno d'Africa. L'ex-impero italiano", in GNISCI, A. (a cura di), Nuovo Planetario Italiano - Geografia e antologia della letteratura della migrazione in Italia e in Europa. op. cit., pp. 241-293.

7 DE LUCA, E., Solo andata - righe che vanno troppo spesso a capo, Milano, Feltrinelli, 2005, p. 25.

$8 I v i$, p. 7.

9 GNISCI, A., "Scrivere nella migrazione tra due secoli", in GNISCI, A. (a cura di), Nuovo Planetario Italiano - Geografia e antologia della letteratura della migrazione in Italia e in Europa. Troina: Città Aperta Edizioni, 2006, pp. 13-39 (18).

10 Cf. CAMILOTTI, S., "L'editoria italiana della letteratura della migrazione", in GNISCI, A. (a cura di), Nuovo Planetario Italiano..., op. cit., pp. 383-391.

11 Cf. LECONTE, M. (a cura di). Ai confini del verso - Poesia della migrazione in italiano. Firenze: Casa Editrice Le Lettere. 2006. p. 5.

12 OSÓRIO, A., "Lição de chinês", in Torno con te a Ulisse, a cura di Guia Boni, Roma, Edizioni Empiria, 2009, pp. 122-123.

\section{Ibidem.}

14 Ver, a tal propósito, o meu ensaio "O lugar e a língua", in Revista de Italianística, Departamento de Letras Modernas, Faculdade de Filosofia, Letras e Ciências Humanas, Universidade de São Paulo, n. XIV, 2006, pp. 97-114.

15 MONTEIRO MARTINS, J., "Il brusio del mondo", in Davide Bregola, Da qui verso casa, Kúmá Lettere Migranti, 2002, pp. 104-127 (116).

16 Cito aqui apenas algumas, mas tantas outras podem ser encontradas em entrevistas e depoimentos publicados em vários sites e, sobretudo, em dois volumes organizados por Davide Bregola, Da qui verso casa, Roma, Edizioni Interculturali, 2002, e Il catalogo delle voci - Colloqui com poeti migrantii, Isernia, Cosmo Ianone Editore, 2005.

17 LECONTE, M., op. cit., p. 8. Justamente por ter deixado de fora, por exigências editoriais, tantos poetas, Mia Leconte se apresta a organizar um segundo volume desta antologia. 


\section{Ibidem.}

19 SAID, E. W., "Riflessioni sull'esilio", op. cit., p.1 27. Todas as traduções, quando não indicado diversamente, são de minha autoria.

20 SAID, E. W., op. cit., p. 129.

21 COLASANTI, M., Passageira em trânsito, Editora Record, Rio de Janeiro, 2009.

22 Cf. ADORNO, T. W., Mínima moralia - meditazioni della vita offesa [1954], Einaudi,Torino, 1994, p. 26.

23 ROLLO, A., "Kundera cercasi", in La Repubblica delle Donne, Supplemento de La Repubblica, Milano, Anno 13º, pp. 81-84 (81).

24 Entrevista com Gëzim Hajdari, in BREGOLA, D. (a cura di), Il catalogo delle vociColloqui con poeti migranti, Cosmo Ianone Editore, Isernia 2005, p. 59.

25 Cf. TADDEO, R. Letteratura nascente. Letteratura italiana della migrazione. Autori e poetiche, Raccolto Edizioni, Milano, 2006.

26 Cf. LECONTE, M., op. cit., p. 11. 